\title{
LETTER
}

\section{Fish oil and sepsis: we still need more trials}

\author{
Flavia R Machado* \\ See related research by Pontes-Arruda et al., http://ccforum.com/content/15/3/R144
}

I read with concern the recently published article by Pontes-Arruda and colleagues addressing eicosapentaenoic acid/ $\gamma$-linolenic acid (EPA/GLA) use in septic patients [1].

First, I did not find an adequate sample size calculation and we should know whether a type I error could have occurred.

Another major concern is the inclusion imbalance among sites, which is not mentioned in the results or as a study limitation. The authors recognized that only five sites included patients among the initial 12 selected sites. As the principal investigator of one of these centers without inclusion, I believe it would be important to mention that the first author's site included the vast majority of patients. Although this is undoubtedly a multicenter study, readers should analyze the results considering exactly how many patients were included from each site and how many were excluded thereafter.

It is not necessary to state the number of patients per site in large, multicenter studies without imbalance. When an imbalance is too high, however, it is advisable to provide possible reasons and to assume that it is a limitation. The authors recognized a limitation only in the highly selected population: patients without organ dysfunction already in the ICU and under enteral nutrition. It is well known that Brazil has a shortage of
ICU beds, mostly in public hospitals, so patients without organ dysfunction are not likely to be admitted.

The patients' baseline characteristics also draw attention, with high Sequential Organ Failure Assessment (SOFA) score, high Multiple Organ Dysfunction Score and hyperlactatemia. Organ dysfunction was one of the exclusion criteria, with quite similar definitions to the SOFA score. The authors should therefore have provided a possible explanation for this finding. The development of organ dysfunction within the 48-hour window to the start of enteral feeding is a possibility. However, this could compromise the results, as organ dysfunction would be already present by the time the intervention took place.

The strong criticism regarding the not yet published EDEN Omega trial is also unusual [2]. This trial will be the strongest evidence for EPA/GLA use and we should wait for a proper peer-review process. I disagree with the authors when they suggest that doctors do not use EPA/ GLA because of these unpublished results. I do believe that the medical community does not widely use fish oil because the available evidence is weak [3-6]. We will need another EPA/GLA trial - multicenter, doubleblinded and well sized for mortality - to finally define its role in early or late sepsis management.

\section{Author's response}

Alessandro Pontes-Arruda

I would like to address the points raised in Dr Machado's letter.

First, the INTERSEPT study was adequately powered and the sample size was calculated to have a $95 \%$ power to detect $5 \%$ reduction in the primary outcome [1].

Second, all relevant limitations were already mentioned in the discussion section of the paper and also made available in a public database (clinicaltrials.gov). The

*Correspondence: fmachado.dcir@epm.br

Anesthesiology, Pain and Intensive Care Department, Federal University of Sao

Paulo R Napoleao de Barros 715 5a andar 04024900 Sao Paulo, SP Brazil results were not compromised by any imbalance; in fact, the independently conducted statistical analysis found that results remained unchanged considering all variables including the inclusion pattern.

Third, the criteria used for definition of organ failures are those depicted in Table 2 of the article [1]. It is perfectly possible for a patient to accumulate some points in the SOFA without fulfilling the prospectively defined criteria for organ failure. For instance, a patient with $\mathrm{PaO}_{2} / \mathrm{FiO}_{2}$ ratio of 350 will have 1 point in the baseline SOFA score, but this is not considered respiratory failure. Similarly, a platelet count of $98,000 / \mathrm{mm}^{3}$ represents 2 points on the SOFA scale but is not considered coagulation failure. A similar pattern is true for all SOFA variables. 
Finally, criticism of the EDEN Omega study is not only necessary but also very appropriate since there are extraordinary methodological differences between the previously published studies [3-5] and the EDEN Omega trial. By the way, this comparison was requested by the reviewers of the paper to make methodological differences crystal clear to Critical Care readers.

The fact is that the evidence for the use of EPA/GLA is extremely strong, as clearly demonstrated by all major nutrition guidelines that unanimously recommended the use of EPA/GLA for the treatment of acute lung injury/ acute respiratory disease syndrome, including the Canadian Guidelines and American Society for Parenteral and Enteral Nutrition/Society of Critical Care Medicine guidelines that gave a grade A recommendation for this strategy $[7,8]$.

\section{Abbreviations}

EPA/GLA, eicosapentaenoic acid/ $Y$-linolenic acid; $\mathrm{PaO}_{2} / \mathrm{FiO}_{2}$, partial pressure of oxygen/fraction of inspired oxygen; SOFA, Sequential Organ Failure Assessment.

\section{Competing interests}

The authors declare that they have no competing interests.

Published: 31 October 2011

\section{References}

1. Pontes-Arruda A, Martins LF, de Lima SM, Isola AM, Toledo D, Rezende E, Maia M, Magnan GB; Investigating Nutritional Therapy with EPA, GLA and Antioxidants Role in Sepsis Treatment (INTERSEPT) Study Group: Enteral nutrition with eicosapentaenoic acid, $\gamma$-linolenic acid and antioxidants in the early treatment of sepsis: results from a multicenter, prospective, randomized, double-blinded, controlled study: the INTERSEPT study. Crit Care 2011, 15:R144.
2. Early Versus Delayed Enteral Feeding and Omega-3 Fatty Acid/Antioxidant Supplementation for Treating People with Acute Lung Injury or Acute Respiratory Distress Syndrome (The EDEN-Omega Study) [http://www. clinicaltrials.gov/ct2/show/record/NCT00609180?term=eden+omega\&rank=1]

3. Gadek JE, DeMichele SJ, Karlstad MD, Pacht ER, Donahoe M, Albertson TE, Van Hoozen C, Wennberg AK, Nelson JL, Noursalehi M: Effect of enteral feeding with eicosapentaenoic acid, $\gamma$-linolenic acid, and antioxidants in patients with acute respiratory distress syndrome. Enteral Nutrition in ARDS Study Group. Crit Care Med 1999, 27:1409-1420.

4. Singer P, Theilla M, Fisher H, Gibstein L, Grozovski E, Cohen J: Benefit of an enteral diet enriched with eicosapentaenoic acid and $y$-linolenic acid in ventilated patients with acute lung injury. Crit Care Med 2006, 34:1033-1038.

5. Pontes-Arruda A, Aragão AM, Albuquerque JD: The effects of enteral feeding with eicosapentaenoic acid, $\gamma$-linolenic acid and antioxidants in mechanically ventilated patients with severe sepsis and septic shock. Crit Care Med 2006, 34:2325-2333.

6. Pontes-Arruda A, Demichele S, Seth A, Singer P: The use of an inflammationmodulating diet in patients with acute lung injury or acute respiratory distress syndrome: a meta-analysis of outcome data. JPEN J Parenter Enteral Nutr 2008, 32:596-605.

7. Martindale RG, McClave SA, Vanek VW, McCarthy M, Roberts P, Taylor B, Ochoa JB, Napolitano L, Cresci G; American College of Critical Care Medicine; ASPEN Board of Directors: Guidelines for the provision and assessment of nutrition support therapy in the adult critically ill patient: Society of Critical Care Medicine and American Society for Parenteral and Enteral Nutrition: executive summary. Crit Care Med 2009, 37:1757-1761.

8. Kreymann KG, Berger MM, Deutz NEP, Hiesmayr M, Jolliet P, Kazandjiev G, Nitenberg G, van den Berghe G, Wernerman J: ESPEN guidelines on enteral nutrition: intensive care. Clin Nutr 2006, 25:210-223.

doi:10.1186/cc10431

Cite this article as: Machado FR: Fish oil and sepsis: we still need more trials. Critical Care 2011, 15:449. 